\title{
Hybrid Element Heuristic Algorithm Optimizing Neural Network-Based Educational Courses
}

\author{
Chunlei Tu, ${ }^{1}$ Yanjin Liu $\mathbb{D}^{2}{ }^{2}$ and Lixiao Zheng ${ }^{1}$ \\ ${ }^{1}$ College of Marxism, Chengdu Textile College, Chengdu, 611130 Sichuan, China \\ ${ }^{2}$ College of International Education, Chengdu Normal University, Chengdu, 611130 Sichuan, China \\ Correspondence should be addressed to Yanjin Liu; 021019@cdnu.edu.cn
}

Received 12 October 2021; Revised 6 November 2021; Accepted 12 November 2021; Published 6 December 2021

Academic Editor: Haibin Lv

Copyright (C) 2021 Chunlei Tu et al. This is an open access article distributed under the Creative Commons Attribution License, which permits unrestricted use, distribution, and reproduction in any medium, provided the original work is properly cited.

\begin{abstract}
The rapid development of computer networks has enabled information technology to penetrate many fields, providing unprecedented opportunities for all aspects of our lives. In order to allow students to acquire necessary knowledge and skills through efficient learning, this article studies the design and development of educational technology courses based on hybrid metaheuristic algorithms to optimize neural networks. This paper proposes a metaheuristic algorithm and explains the simulated annealing algorithm and microregular annealing algorithm in detail. Using these algorithms, a mathematical model of the normal scheduling problem was also constructed, and the mathematical model was applied to the design and development of educational technology courses. In addition, the neuron model in the neural network and the activation function of the neural network are discussed from various aspects. In the experiment, according to the needs of students, a learning platform for educational technology courses was designed and developed. The experimental results of this article show that there are significant differences in the starting point of the ability level of learners for different majors. Education majors have a higher level of understanding of educational technology courses; $38.20 \%$ of students know well, while art majors have a low level of understanding of education technology courses, with $36.05 \%$ of students majoring in art.
\end{abstract}

\section{Introduction}

In the process of deepening education reform, cultivating high-quality talents with innovative spirit has become the historical mission of education. The widespread application of modern information technology in education is represented by multimedia and network technology. It has had a significant impact on the traditional teaching style, teaching methods, content, and teaching methods. Correspondingly, the application of network technology in teaching is more and more extensive, and the form of networked teaching is becoming more and more abundant. MOOC, microclasses, and online learning have all become new forms of education in the Internet age. "Education should face modernization, face the world, and face the future," and the use of new educational technology is one of the measures of education modernization. Schools of all levels and types should carry out current educational technology activities and fully apply new educational technology methods to specific teaching activities.
The ability of educational technology undoubtedly occupies an important position in the professional skill system of teachers. The advantage of the traditional classroom is that it can play the leading role of teachers, the teaching level is quite high, and it can also promote the emotional exchange between teachers and students. The disadvantage is that the basic role of students is not fully reflected, resources are limited, and students rely on teachers to a high degree. Through online learning, students can use computer communication and multimedia technology for multidimensional, resourceintensive, time-limited, and personalized learning. The problem is that the role of teachers is not fully reflected, and students' "learning ability" is obviously limited. In this case, we need to learn how to better design and develop educational technology courses. The analysis of learning needs is the prerequisite of teaching planning. The success or failure of learning need analysis is related to the success or failure of teaching results, which helps to understand the real needs of educational technology teaching, provide teaching design to meet 
the individual learning needs of students in different disciplines, and also help improve students' academic performance.

Regarding the design and development of educational technology courses, scholars at home and abroad have conducted research on this. Ritzhaupt et al. designed to document the design, development, and evaluation of statistical courses tailored for doctoral students in educational technology in an online program. Using quantitative and qualitative data sources, it proved the use of real and relevant data sets based on peer-reviewed publications in the field of education technology, and it was found that students' statistical anxiety levels decreased significantly in three key areas [1]. Olusola and Kolapo investigated the perceptual relevance of preservice teachers to educational technology content, digital tools, and their performance in educational technology courses. This study was conducted on 261 preservice teachers, and the results showed that students' perception of educational technology courses is highly relevant. The correlation coefficient is 0.015 , which shows the positive correlation between preservice teachers' perception of educational technology courses and the final exam scores of the course semester [2]. Matsukawa et al. use topic modeling based on potential Dirichlet assignments to analyze approximately 60,000 data sets collected by a university over the past nine years to analyze the free descriptions obtained through the course evaluation questionnaire. Then, according to a series of steps, the extracted 170 topics were annotated, and the effectiveness of the annotation was verified [3]. Sletten aims to examine the relationship between two variables, namely, students' perceptions of the flipped model and their self-regulated learning (SRL) behavior, and the impact of these variables on flipped classroom performance. In this study, 76 participants from the flipped introductory biology course were asked about their views on the use of the SRL strategy and the flipped model. Through regression analysis, it is found that students' cognition of the flip model positively predicts students' use of several SRL strategies [4]. In order to explore the development of self-regulation in the flipped classroom environment, Çakıroğlu and Öztürk conduct problembased learning activities in the flipped classroom to promote self-regulation. Thirty undergraduates from the Department of Mechatronics participated in this study. Through the experiences of students and teachers, including their opinions and behaviors, self-regulation skills are discussed [5]. Huang et al. investigated the characteristics of deep and superficial learning methods in online students' responses to teachers' qualitative feedback on multistage, poorly structured design projects. In addition, it examines the relationship between learning methods and two learner characteristics: cognitive beliefs (EB) and closed needs (NFC). Four emerging themes were identified, in which the learning methods of students spread from deep to superficial learning: the number of feedback items processed, the understanding of feedback, the quality of processing feedback, and overall thinking [6]. Hussain et al. adopt a student-centered approach and implement a "flipped classroom" model in engineering courses to achieve constructivism (i.e., learning based on experience) and individualized learning for students. A new method based on fuzzy logic is designed to evaluate students' survey responses from qualitative survey data. The flipped classroom model helps students improve their grades and strengthen their interaction with teachers and peers [7]. The results of these studies may all help other scholars to strive to achieve personalized learning based on experience and students, but their research is not comprehensive.

The innovations of this paper are the following: (1) This paper introduces a metaheuristic algorithm to solve the optimization problem and chooses the simulated annealing algorithm and the microregular annealing algorithm suitable for this research to solve the problem. (2) The design and development of educational technology courses based on the hybrid metaheuristic algorithm to optimize the neural network, which is studied in this paper, use the fusion of metaheuristic algorithm and artificial neural network to solve the current problems in the field.

\section{Design and Development Method of Educational Technology Courses Based on the Hybrid Metaheuristic Algorithm to Optimize the Neural Network}

2.1. Metaheuristic Algorithm. Compared with the optimization algorithm, the metaheuristic algorithm is an improvement of the heuristic algorithm [8,9]. It combines two types of random algorithms and local search algorithms and, aiming at a specific problem, iteratively obtains an approximate optimal solution that can be used to calculate a given problem under the complexity of time and the complexity of a given area [10]. The overview diagram of the metaheuristic algorithm is shown in Figure 1.

2.1.1. Simulated Annealing Algorithm. The simulated annealing algorithm is derived from the principle of solid annealing and is a probability-based algorithm. The solid is heated to a sufficiently high level and then allowed to cool down slowly; when heating, the internal particles of the solid become disordered with the temperature rise, and the internal energy increases. When cooling slowly, the particles gradually become orderly, reaching an equilibrium state at each temperature and finally reaching the ground state at room temperature, and the internal energy is reduced to a minimum. The simulated annealing algorithm is an extension of the local search algorithm [11]. Different from the local search algorithm, it selects the high-cost state in the neighborhood with a certain probability. This is a proposed global search algorithm. The general algorithm flow of the simulated annealing method is shown in Figure 2.

2.1.2. Microregular Annealing Algorithm. The microregular annealing algorithm was proposed by Michael Creutz in 1983, and it is also the process of simulated annealing, but the microregular annealing algorithm focuses on the energy change process of the system, not the change of the system temperature $[12,13]$. Among them, in the simulated annealing algorithm, there is a process of a greedy mechanism, which can accept a new state that increases the value of the objective function and uses another mechanism to accept a new state that deteriorates the value of the objective function 


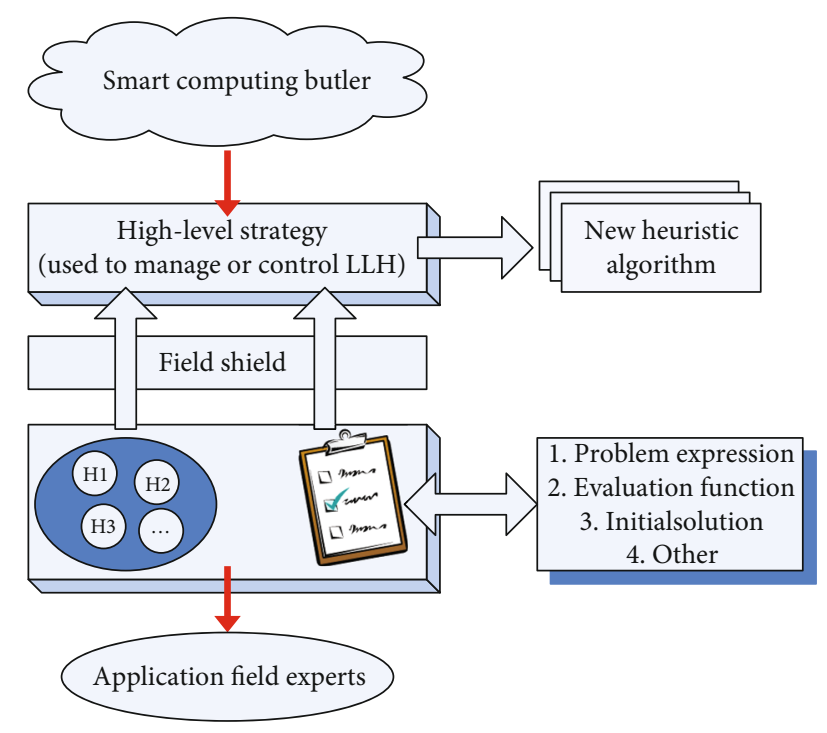

FIgURE 1: Overview of metaheuristic algorithm.

to a certain extent. The conditions for deteriorating the new state are becoming more and more demanding, and the poor state is accepted with a small probability according to the Metropolis criterion [14]. Compared with these two mechanisms, only one mechanism is used in the microregular annealing algorithm to accept the next state. It accumulates all the energy to change $\sum \Delta E$ in each inner cycle of annealing and accepts the current bad state as long as the accumulated energy $\sum(-\Delta E)$ taken away is positive.

The microcanonical Monte Carlo simulation method is based on the concept of microcanonical system [15]. In this simulation technology, $\beta$ is no longer directly dependent, and the form of the distribution function $Z$ becomes

$$
A=\sum_{B} \sum_{C} \delta\left[E(B)+K(C)-E_{0}\right]
$$

where $E_{0}$ is the initial energy value and $K(C)$ is the energy of momentum $C$ in state $B$.

Assume that $E_{D}$ is a positive number and the initial value is generally equal to zero. At this time, the form of $Z$ is

$$
A=\sum_{B} \sum_{E_{D}} \delta\left[E(B)+E_{D}-E_{0}\right]
$$

The initial system state can be arbitrarily configured. When released with 0 initial energy, it will randomly enter the state area and try to modify the current state. If this action can reduce the power consumption of the system, it will absorb the energy difference involved $[16,17]$, which is

$$
E_{D}^{\prime} \longleftarrow E_{D}+E_{J}+E_{I}
$$

Among them, $E_{I}$ and $E_{J}$, respectively, represent the system energy corresponding to the old and new distribution schemes.
2.2. Mathematical Model of Normal Arrangement Problem. When the conventional scheduling problem cannot be solved manually, the simulated annealing algorithm and the microrule algorithm in the metaheuristic algorithm used in this article are used to solve the conventional scheduling problem.

There are $x$ students, $y$ subjects, and $r$ classes. Each student $i$ 's grade for each subject is $S_{i u}$. Most students will have old classmates or friends, and sometimes, some of them will have "enemies" who often conflict. For each student, there are two corresponding lists containing old classmates and enemies of the same gender. All students will be assigned to $r$ classes.

$i$ represents the $i$ th student, $i \in\{1,2, \cdots, x\} ; u$ represents the $u$ th subject, $u \in\{1,2, \cdots, y\} ; k$ represents the $k$ th class, $k$ $\in\{1,2, \cdots, q\} ; a(i)$ represents the gender of the student $i$, equal to 1 is a girl, and equal to 0 is a boy; $M_{i k}$ is a binary variable; when $M_{i k}=1$, student $i$ is assigned to the $k$ th class; when $M_{i k}=0$, the opposite is true, because a student can only be assigned to one class, so there is $\sum_{k=1}^{q} M_{i k}=1 ; N_{i k}$ is a binary variable, when $N_{i k}=1$ means student $i$. If you are assigned to class $k$ and do not have an old classmate of the same gender, the opposite is true when $N_{i k}=0$, there is obviously $\sum_{k=1}^{q} N_{i k} \leq 1 ; W_{k}$ is an integer variable that indicates how many conflicting pairs of students in class $k$.

The similarity of the number of people in each class can be expressed as the value of the following formula as small as possible:

$$
\min \left(\max _{k=1}\left\{\sum_{i=1}^{x} M_{i k}\right\}-\min _{k=1}\left\{\sum_{i=1}^{x} M_{i k}\right\}\right) .
$$

A similar number of girls in each class can be expressed as the value of the following formula as small as possible, and similar formulas can be used for boys:

$$
\min \left(\max _{k=1}\left\{\sum_{i=1}^{\mathrm{x}} M_{i k} a(i)\right\}-\min _{k=1}\left\{\sum_{i=1}^{x} M_{i k} a(i)\right\}\right) .
$$

The students in each class have at least one old classmate of the same gender, which can be expressed as the value of the following formula as small as possible:

$$
\min \left(\max _{k=1}\left\{\sum_{i=1}^{x} N_{i k}\right\}\right) \text {. }
$$

Students who have had conflicts should avoid being placed in the same class, which can be expressed as the value of the following formula as small as possible:

$$
\min \left(\max _{k=1}\left\{W_{k}\right\}\right) \text {. }
$$

For course $u$, we can calculate the average grade of each class $k$. The difference between the maximum average score and the minimum average score in all classes can be used as a scalar for the difference in the course scores. All courses 


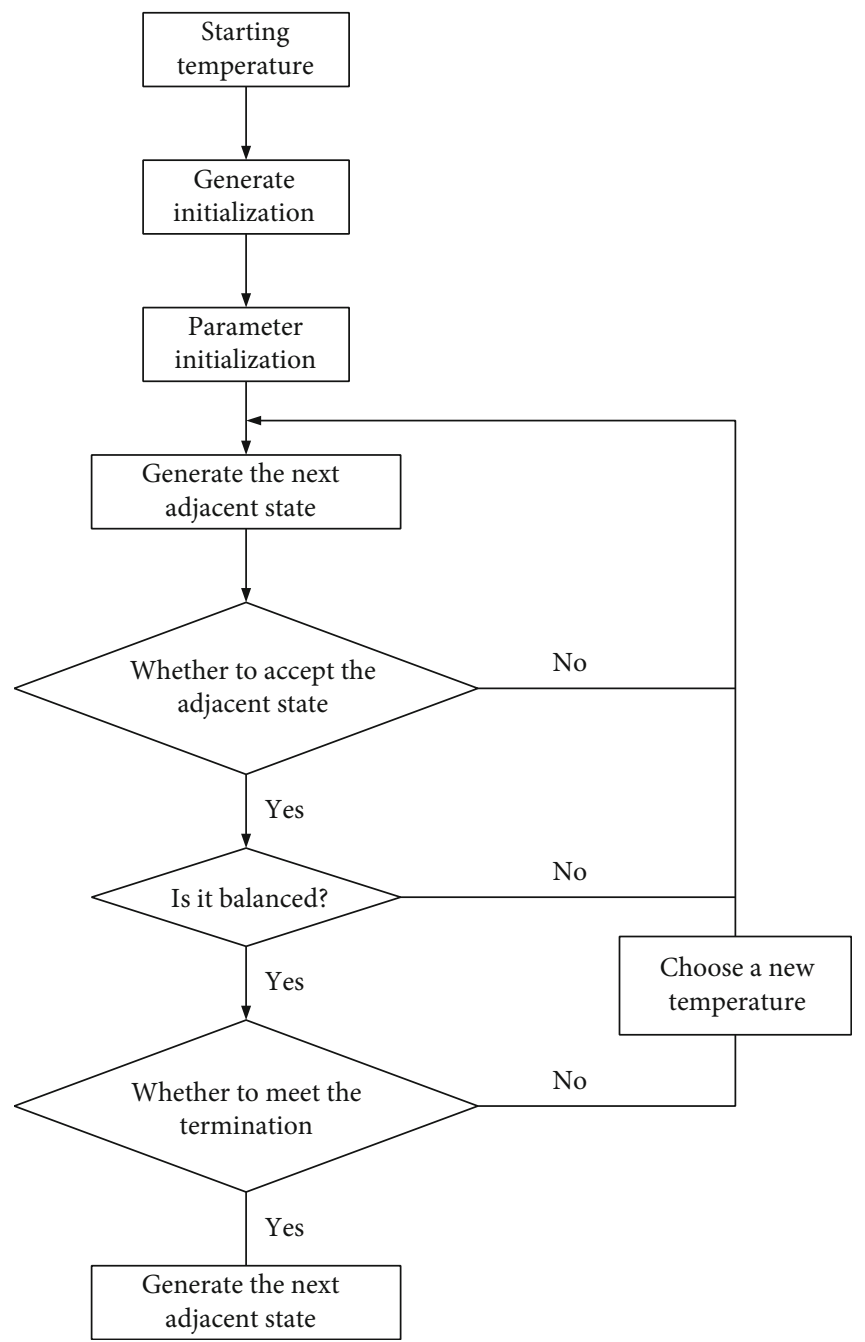

FIGURE 2: Block diagram of simulated annealing algorithm.

have similar average grades in each class, which can be expressed as the value of the following formula as small as possible:

$$
\min _{u=1}\left\{F_{u}^{5}\left(\max _{k=1}\left\{\frac{\sum_{i=1}^{x} M_{i k} S_{i u}}{\sum_{i=1}^{x} M_{i k}}\right\}-\min _{k=1}\left\{\frac{\sum_{i=1}^{x} M_{i k} S_{i u}}{\sum_{i=1}^{x} M_{i k}}\right\}\right)\right\},
$$

where $F_{\mathrm{u}}^{5}$ is the average weight of the course $u$.

For the course $u$, we can sort students' grades from small to large, use $H_{u k}(D)$ to represent the highest grade of $D$, and divide this sequence into $[x / q]$ parts; excluding the last part, every other part has $q$ elements; each part can calculate the average score:

$$
s_{u}(l)=\sum_{D=l q}^{l q+q-1} H_{u} \frac{(D)}{q}
$$

where $l$ is a nonnegative number less than or equal to $[x / q]$. From these average grades, we can construct the score of a template class. This class has $[x / q]$ students, and the grade is $s_{u}(l)$. Then, we use $H_{u k}(D)$ to represent the student scores of the ranking $D$ of the course $u$ in class $k$. The following formula is the standard deviation of the grades of course $u$ for class $k$ and template class, denoted by $B$ :

$$
B=\sqrt{\sum_{D=1}^{\sum_{i=1}^{x} M_{i k}}\left(s_{u}(D)-H_{u k}(D)\right)^{2}} .
$$

The similarity of the score distribution of each course in each class can be expressed as the value of the following formula as small as possible:

$$
\min _{u=1}\left\{F_{u}^{6} \max _{k=1}\left\{\sqrt{\sum_{D=1}^{\sum_{i=1}^{x} M_{i k}}\left(s_{u}(D)-H_{u k}(D)\right)^{2}}\right\}\right\}
$$

where $F_{u}^{6}$ is the distribution weight of course $u$. 
Now, we can get the formula that considers all factors at the same time:

$$
\begin{gathered}
\min \left(F^{1}\left(\max _{k=1}\left\{\sum_{i=1}^{x} M_{i k}\right\}-\min _{k=1}\left\{\sum_{i=1}^{x} M_{i k}\right\}\right),\right. \\
F^{2}\left(\max _{k=1}\left\{\sum_{i=1}^{x} M_{i k} a(i)\right\}-\min _{k=1}\left\{\sum_{i=1}^{x} M_{i k} a(i)\right\}\right), \\
F^{3} \max _{k=1}\left\{\sum_{i=1}^{x} N_{i k}\right\}, \\
F^{4} \max _{k=1}\left\{W_{k}\right\} .
\end{gathered}
$$

Add formula (8) to formulas (12), (13), (14), and (15), and add

$$
F_{u}^{6} \max _{k=1}\left\{\sqrt{\sum_{D=1}^{\sum_{i=1}^{x} M_{i k}}\left(s_{u}(D)-H_{u k}(D)\right)^{2}}\right\} .
$$

Among them, $F^{1}, F^{2}, F^{3}, F^{4}, F_{u}^{5}$, and $F_{u}^{6}$ are the calculation weights of the corresponding formulas. The function value of the sum of these formulas is called the objective function value. It can be known from the derivation process of the formula that the smaller the objective function value, the better the current result, which means that the current result meets the requirements.

\subsection{Neural Network}

2.3.1. Neuron Model. The basic processing unit of a neural network is a neuron, which is a simulation of a biological neuron $[18,19]$. The connection between each neuron and its corresponding neuron is biologically called a synapse. In the mathematical model, we call each synapse the weight of the network, and the neural network trains the network by adjusting these weights $[20,21]$.

$x_{1}, x_{2}, \cdots, x_{n}$ represents the input of the neuron, and $\omega_{i 1}, \omega_{i 2}, \cdots, \omega_{\text {in }}$ is the connection weight. Use a certain calculation to combine the effects of the input signal to give the total effect, expressed by net ${ }_{i}$. According to different calculation methods, the expression of net ${ }_{i}$ is different. The following is the simplest linear weighted summation form, namely,

$$
\text { net }_{i}=\sum_{j=1}^{n} \omega_{i j} x_{j} \text {. }
$$

The output $y_{i}$ is the value after the action of the excitation function $f$. In this way, the mathematical expression of the above model is

$$
\begin{gathered}
\text { net }_{i}=\sum_{j=1}^{n} \omega_{i j} x_{j}-\theta_{i}, \\
y_{i}=f\left(\text { net }_{i}\right) .
\end{gathered}
$$

In the formula, $\theta_{i}$ is the threshold of neuron $i$ and net ${ }_{i}$ is the net input, which is the total effect of combining the effects of the input signal by a certain operation.

2.3.2. The Excitation Function of the Neural Network. After the neuron gets the network input, it should give the corresponding output [22]. Used to perform the transformation of the network input obtained by the neuron, this is the activation function, also known as the activation function [23, 24]. Typical activation functions are linear function, nonlinear function, threshold function, and sigmoid function. The four function images are shown in Figure 3.

2.3.3. Linear Function. The most basic activation function in a neural network is a linear function, and its role is to appropriately amplify the input signal obtained by the neuron [25]. Its form is

$$
f(\text { net })=k \times \text { net }+c .
$$

In the formula, $k$ is the magnification factor and $c$ is the displacement. Both $k$ and $c$ are constants.

2.3.4. Nonlinear Ramp Function. Choosing a linear function will affect the performance of the neural network and may also make the performance of a multilevel neural network become a single-level network. Therefore, we introduce a nonlinear ramp function.

The nonlinear ramp function is a piecewise linear function. The value range of the function is in the range $[-\gamma, \gamma]$ :

$$
f(\text { net })= \begin{cases}\gamma, & \text { net } \geq \theta \\ k \times \text { net, } & \mid \text { net } \mid<\theta \\ -\gamma, & \text { net } \leq-\theta\end{cases}
$$

Among them, $\gamma$ is a constant, and $\gamma>0$ is usually specified. It is called the saturation value, which is the maximum output of the neuron.

2.3.5. Threshold Function. The threshold function is also called the step function. Its function is to determine whether the network input obtained by the neuron exceeds the set value $\theta$. The form of the function is

$$
f(\text { net })= \begin{cases}\beta, & \text { net }>\theta, \\ -\gamma, & \text { net } \leq \theta,\end{cases}
$$

where $\beta, \gamma$, and $\theta$ are all nonnegative real numbers and $E E$ is the threshold.

Usually, people use its binary form:

$$
f(\text { net })= \begin{cases}1, & \text { net }>\theta, \\ 0, & \text { net } \leq-\theta .\end{cases}
$$

Sometimes, 0 in the above formula is also changed to -1 ; then, it becomes the following form: 


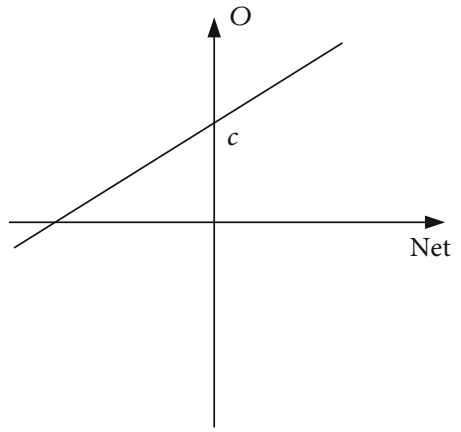

(a)

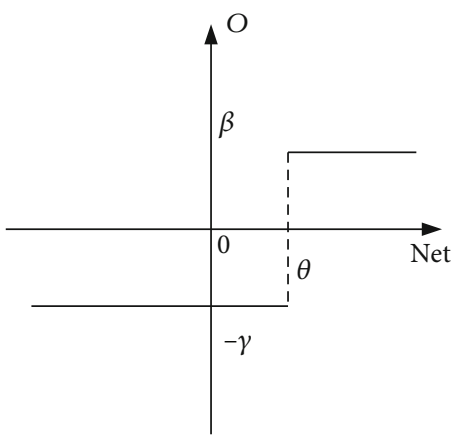

(c)

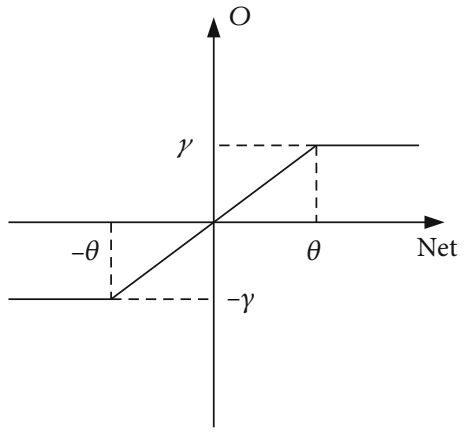

(b)

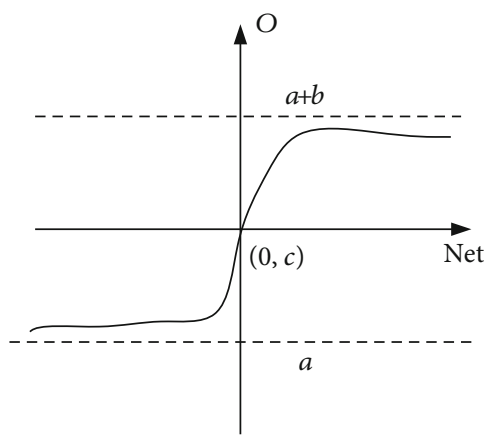

(d)

FIgURE 3: Four activation function images.

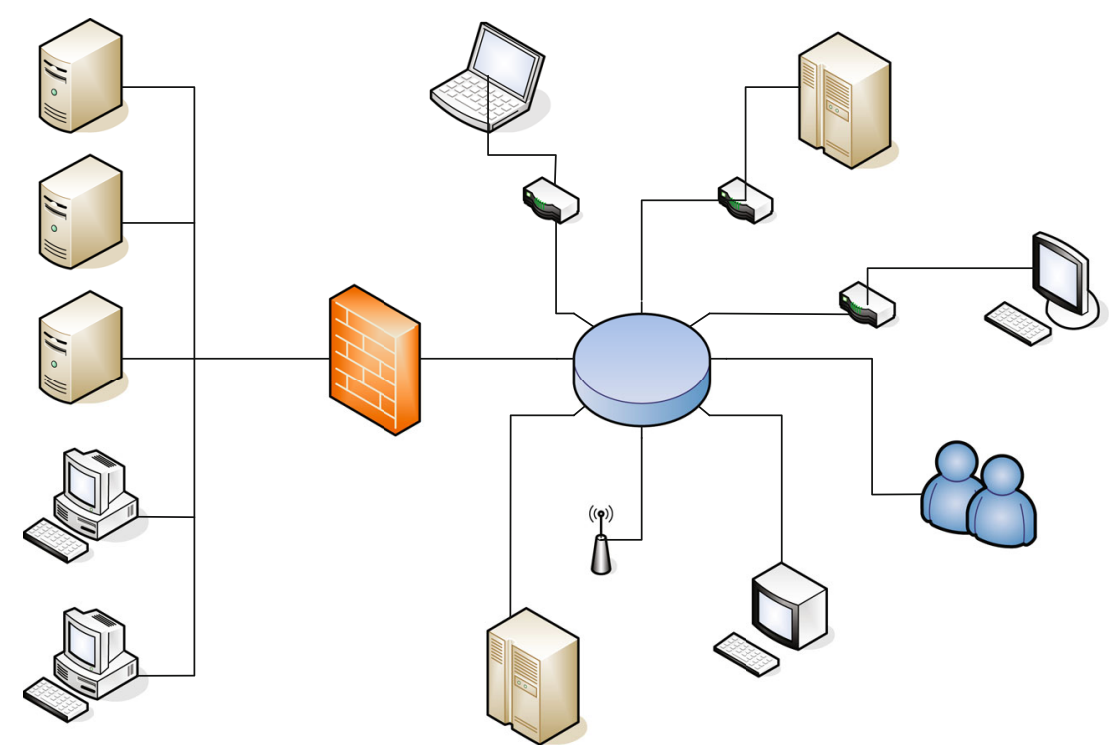

FIGURE 4: B/S structure.

$$
f(\text { net })= \begin{cases}1, & \text { net }>\theta, \\ -1, & \text { net } \leq-\theta .\end{cases}
$$

2.3.6. S-Shaped Function. The sigmoid function is also called the compression function, and it is the most widely used. The sigmoid function is also called the logistic function. It is used for the output of hidden layer neurons. The value range is $(0,1)$. It can map a real number to the interval of
$(0,1)$ and can be used for binary classification. The effect is better when the feature difference is more complicated or the difference is not particularly large. Its form is

$$
f(\text { net })=a+\frac{b}{1+\exp (-d \times \text { net })} \text {. }
$$

In the formula, $a, b, d$ are constants. 


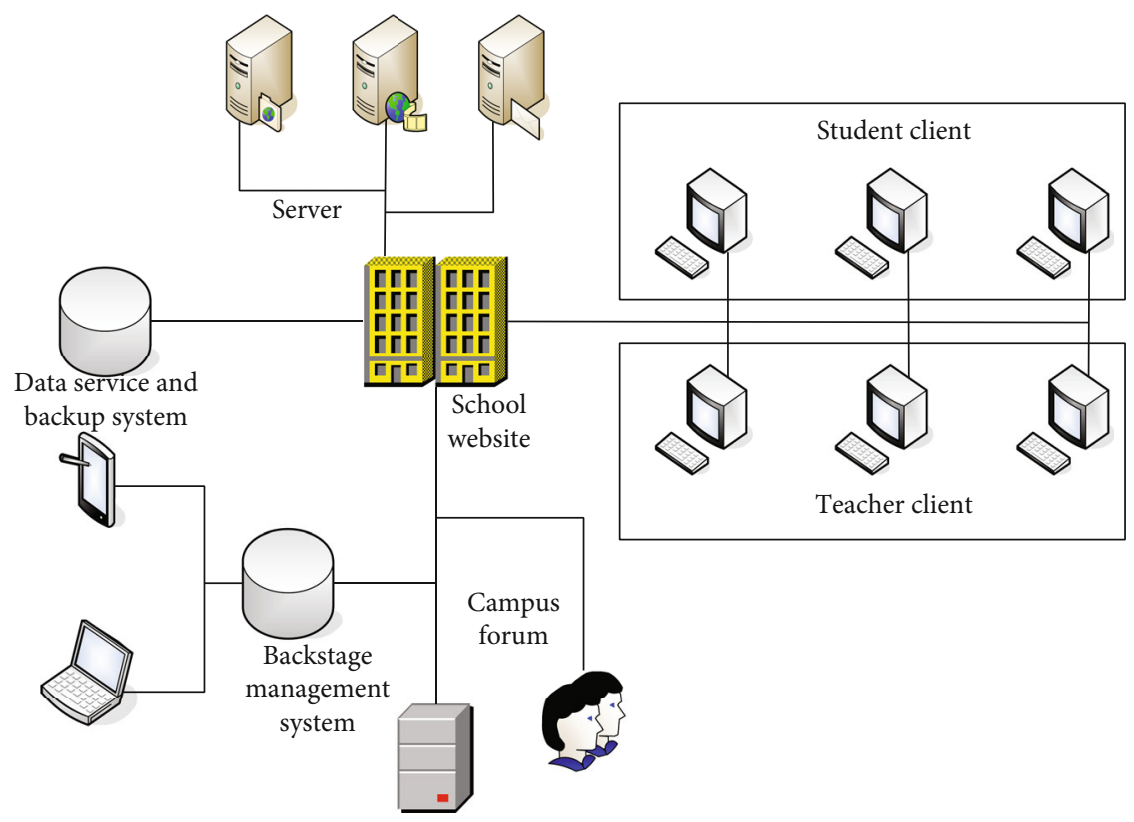

Figure 5: Topology diagram of learning platform system architecture.

The general form of this function is

$$
f(\text { net })=\frac{1}{1+\exp (-d \times \text { net })} \text {. }
$$

At this time, the saturation value of the function is 0 and 1 , and the hyperbolic function or extended square function can also be used. When taking the expansion function,

$$
f(\text { net })= \begin{cases}\frac{\text { net }^{2}}{1+\text { net }}, & \text { net }>0 \\ 0, & \text { else }\end{cases}
$$

The saturation values are still 0 and 1 . When taking the hyperbolic function,

$$
f(\text { net })=\tan (\text { net })=\frac{e^{\text {net }}-e^{- \text {net }}}{e^{\text {net }}+e^{- \text {net }}} .
$$

Saturation values are -1 and 1 .

\section{Experiments and Experimental Results}

3.1. Learning Resource Needs. Learning resources are all things that can help a person study and work effectively. In a broader sense, learning resources are the general term for things that provide learning. Learning resources support and promote learning. It should also include elements such as personnel, tools, strategies, methods, and environment. Learning resources in a narrow sense refer to learning content and learning resources, providing platform-based learning resource design to meet teaching and learning needs. The quality of platform resources directly affects students' learning interest and enthusiasm and also affects students' academic performance $[26,27]$. The research process of this
TABLE 1: Contrast table of $\alpha$ coefficient value and reliability degree.

\begin{tabular}{lc}
\hline$\alpha$ value & Reliability \\
\hline$\alpha<0.5$ & Unacceptable \\
$0.5 \leq \alpha<0.6$ & Acceptable \\
$0.6 \leq \alpha<0.7$ & Generally \\
$0.7 \leq \alpha<0.8$ & High reliability \\
$0.8 \leq \alpha<0.9$ & High confidence \\
$\alpha \geq 0.9$ & Very high reliability \\
\hline
\end{tabular}

experiment is carried out through the method of a questionnaire survey, which analyzes the views of learners on learning resources and also provides different kinds of learning resources.

3.2. Overall Design of the Platform. According to demand analysis, a learning platform for educational technology courses is designed and developed. The main modules of the platform include the student service center, curriculum resource center, teacher service center, interactive communication center, and management center.

3.2.1. B/S Structure. The B/S structure, that is, the client only needs to access the server resources through the browser, is a change and improvement to the $\mathrm{C} / \mathrm{S}$ structure. The common architecture diagram of the $\mathrm{B} / \mathrm{S}$ structure is shown in Figure 4 . The $\mathrm{B} / \mathrm{S}$ architecture is an improvement from the $\mathrm{C} / \mathrm{S}$ architecture, which can be said to be a three-tier $\mathrm{C} / \mathrm{S}$ architecture, which shows that the relationship between the two is not general. B/S broke away from $\mathrm{C} / \mathrm{S}$. Later, with the rapid development of WEB technology and the deepening of people's dependence on the network, B/S became the most popular network architecture in one fell swoop. 
TABLE 2: Reliability test results.

\begin{tabular}{lcc}
\hline$\alpha$ value & Number of questions & Reliability \\
\hline Status of learner skills and knowledge & 8 & 0.768 \\
The status of the learner's theoretical knowledge & 7 & 0.794 \\
Total table & 15 & 0.775 \\
\hline
\end{tabular}

TABLE 3: KMO factor analysis and evaluation criteria.

\begin{tabular}{lcc}
\hline Detection category & Range of values & Factor analysis suitability \\
\hline & $>0.9$ & Very suitable \\
& $0.8-0.9$ & Very suitable \\
& $0.7-0.8$ & Fit \\
KMO value & $0.6-0.7$ & Not very suitable \\
& $0.5-0.6$ & Barely fit \\
& $<0.5$ & Not suitable \\
\hline Bartlett $P$ value & $\leq 0.01$ & Fit \\
\hline
\end{tabular}

3.2.2. Multilayer Structure Mode. The multilayer structure pattern is developed on the basis of the three-layer structure pattern. The business logic layer in the three-layer structure pattern is further decomposed according to the needs and decomposed into more layers. This system uses a multilayer structure model in the development structure, which is composed of five layers: user interface, business logic layer, business rule layer, data access layer, and database, as shown in Figure 5.

3.3. Design of the Questionnaire. The main purpose of designing the questionnaire is to determine the needs of the learners of educational technology courses and the needs of the learners for blended teaching. The overall questionnaire is designed mainly through three aspects: the basic background of learners, teaching needs, and educational technology learning needs. Then, it is divided into five small parts. The first part is mainly to obtain the personal background information of the survey object and the background of the survey object. The second part mainly obtains the actual learning needs of the surveyed subjects in offline learning. The third part is to obtain the actual needs of the survey respondents in traditional online classrooms. The fourth part is presented in the form of a scale, which is divided into five levels. It mainly obtains the knowledge level of the survey subjects before learning the content of educational technology courses and investigates the starting level of the two types of knowledge, software skill level and theoretical knowledge. The fifth part is mainly to obtain the survey object's learning expectations in educational technology courses.

Since the online questionnaire survey tool is relatively mature, the questionnaire is divided into two parts. The questionnaires are distributed on a trial basis using manual and online questionnaire survey platforms, which can save manpower, material resources, and financial resources and help data collation and analysis. The trial issuance of the questionnaire is to test the rationality of the questionnaire itself, whether it meets the research requirements and whether the results obtained meet the purpose of the research. Whether the questionnaire meets expectations, it is necessary to pass the reliability and validity test of the questionnaire.

3.3.1. Reliability Analysis of the Questionnaire. In this study, the questionnaire used the alpha coefficient method established by Cronbach to test the reliability, which is the commonly used reliability test in the attitude scale method. Different research scholars have given different limits for the boundary value of the $\alpha$ coefficient, as shown in Table 1 .

In this study, a preliminary questionnaire was issued to 50 learners of education majors. The effective data was 50 . The reliability of the returned questionnaire was analyzed through SPSS22. The test results are shown in Table 2.

It can be seen from Table 2 that the scale is used to test the skills, knowledge, ability, and theoretical knowledge of educational professional learners, and the questionnaire scale $\alpha$ value is 0.775 , greater than 0.7 , indicating that the test scale has high overall reliability and high internal consistency. On the current situation of learners' skill knowledge, the $\alpha$ coefficient value is 0.768 , greater than 0.7 , indicating that this part has high item reliability and does not need to make major changes to this topic.

3.3.2. Validity Analysis of Questionnaire. In this study, the validity of the overall questionnaire is analyzed. Before the validity analysis of the questionnaire, the KMO value analysis of the data is first tested. The KMO value is the standard to judge whether the data is suitable for factor analysis. The expression boundary of the KMO value is shown in Table 3.

3.4. Experimental Investigation Results. Figure 6 shows the survey results of students' grades, genders, and majors.

The survey results of students' learning styles and learning resource types are shown in Figure 7.

It can be seen from Figure 7 that for the learning method of online learning resources, a total of $94 \%$ of students will choose to use online learning as the primary or secondary learning method, and only $6 \%$ use other learning methods, indicating that most learners prefer online learning $[28,29]$.

A survey of online learning resources frequently used by learners found that $42 \%$ chose to use textual materials; $29 \%$ chose to use video and audio learning resources, such as sound files and video files; $18 \%$ chose online courses, for example, learning recorded in the classroom; $11 \%$ choose other learning resources. 

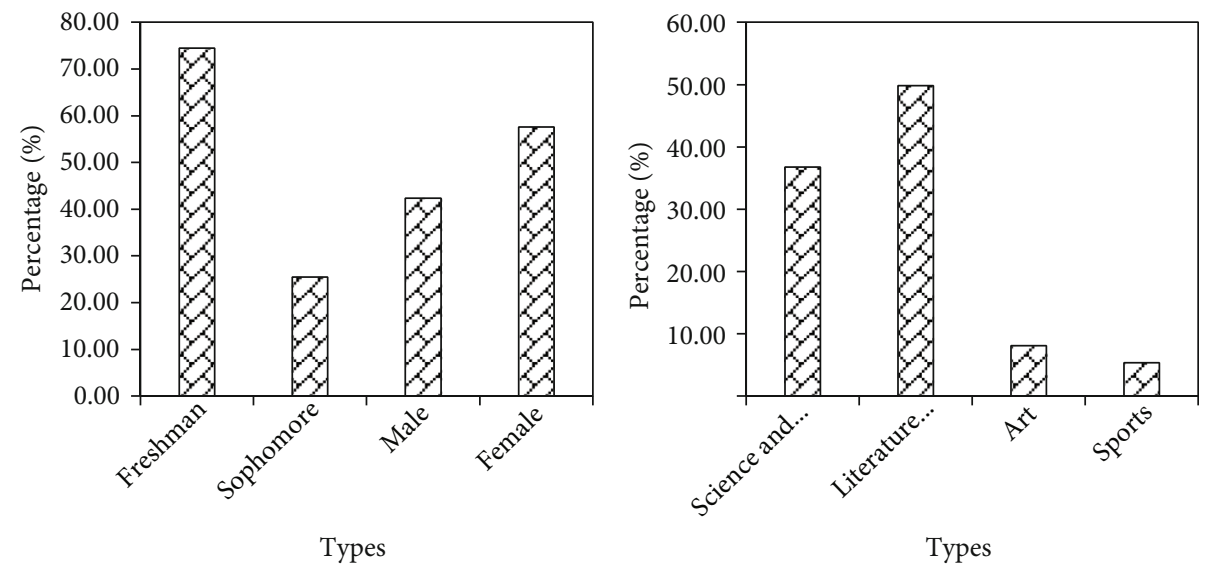

The proportion

FigURE 6: The basic situation of the survey object.
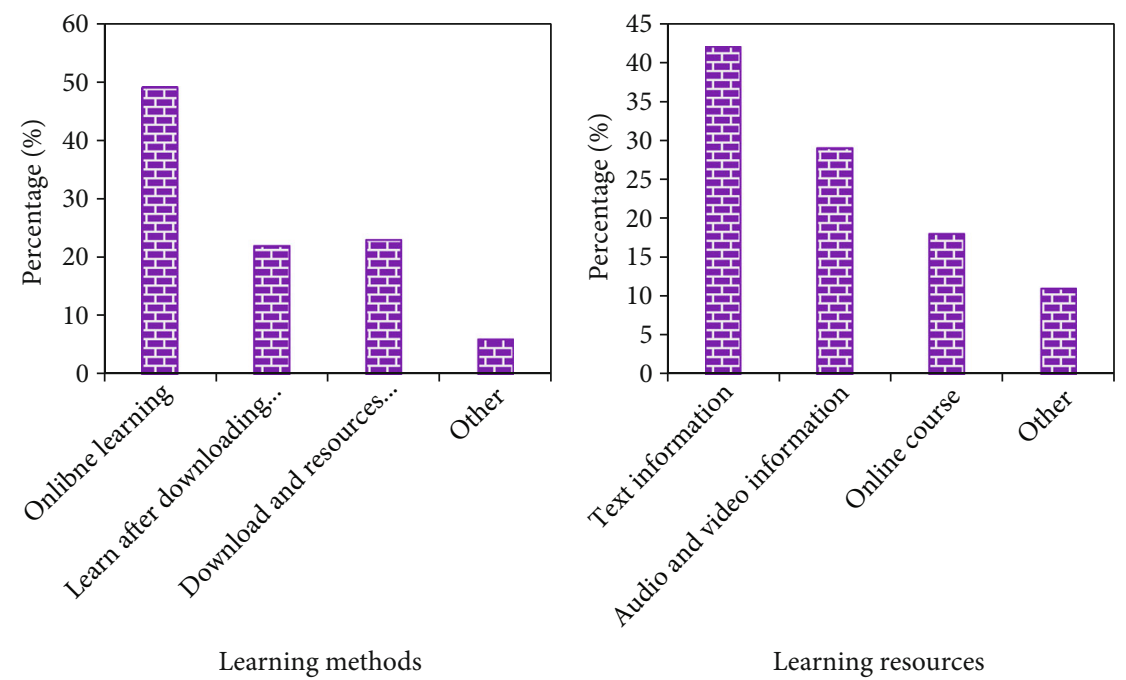

The proportion

FIGURE 7: Survey results of students' learning styles and types of learning resources.
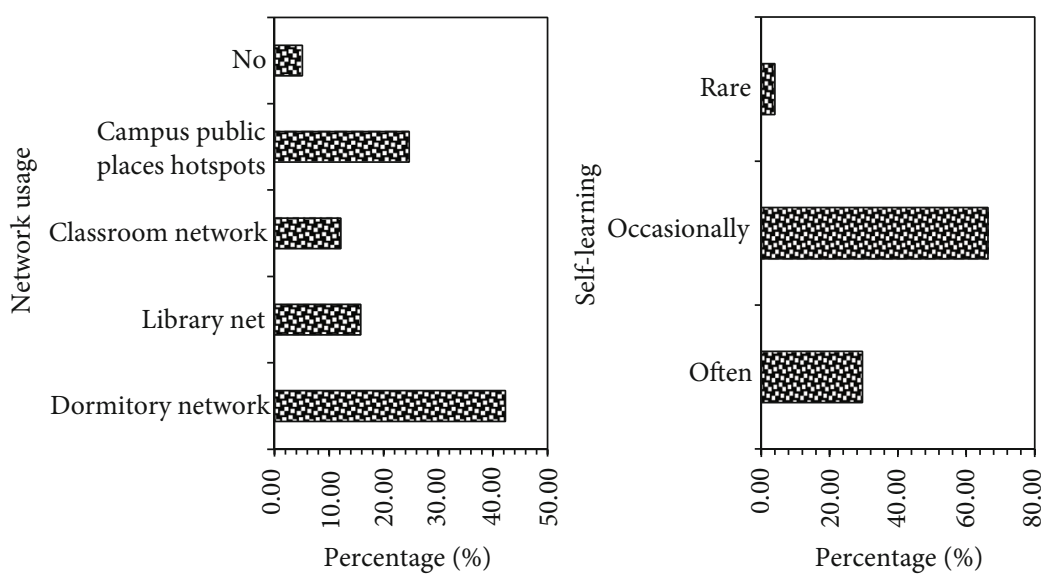

由 The proportion

FIGURE 8: Survey results of students' use of the Internet and autonomous learning. 


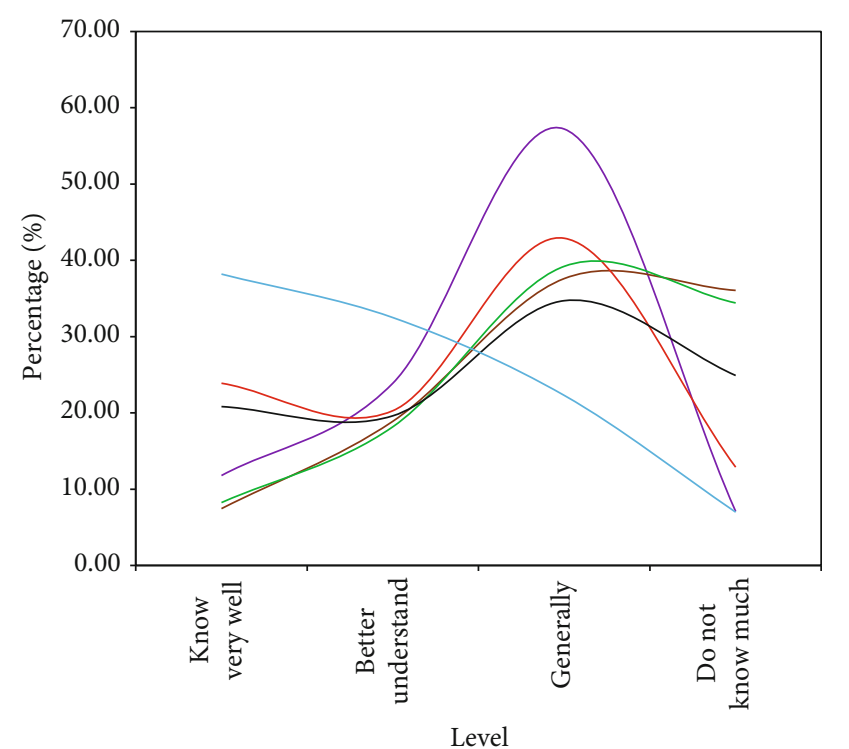

$\begin{array}{ll}- \text { Science and engineering } & - \text { Sports } \\ \text { Art } & - \text { Medicine } \\ - \text { Literature and history } & - \text { Education }\end{array}$

FIgURE 9: Scale-level statistical results of different professions.

TABLE 4: Software skill level of learners.

\begin{tabular}{lccc}
\hline Type & $\begin{array}{c}\text { Number of valid } \\
\text { values }\end{array}$ & $\begin{array}{c}\text { Number of missing } \\
\text { values }\end{array}$ & $\begin{array}{c}\text { Average } \\
\text { value }\end{array}$ \\
\hline $\begin{array}{l}\text { PowerPoint } \\
\text { Adobe }\end{array}$ & 575 & 0 & 1.94 \\
$\begin{array}{l}\text { Photoshop } \\
\text { Adobe Flash }\end{array}$ & 575 & 0 & 2.61 \\
$\begin{array}{l}\text { Adobe } \\
\text { Captivate }\end{array}$ & 575 & 0 & 2.63 \\
$\begin{array}{l}\text { Premiere, AE } \\
\text { Camtasia }\end{array}$ & 575 & 0 & 2.98 \\
Studio & 575 & 0 & 2.72 \\
\hline
\end{tabular}

The survey results of students' use of the Internet and autonomous learning are shown in Figure 8.

In terms of Internet usage, the Internet is used in the dormitory the most, with $42.3 \%$ of students using Internet in the dormitory. In terms of self-directed learning, $29.65 \%$ of students will study independently on a regular basis, and the number of people who study independently occasionally accounts for $66.37 \%$ of the total number of students, of which only $3.98 \%$ of students rarely study independently. From the data point of view, most learners have experience of autonomous learning or often learn independently, and the online learning of this teaching mode requires learners to carry out autonomous learning, and the ability of autonomous learning plays an important role in promoting teaching.

This study investigated the theoretical knowledge and skills currently possessed by learners of different majors by formulating a scale. The scale is divided into five levels, namely, "very understanding," "comprehensive understanding," "average," "not so familiar," and "never heard." The potential meaning of the average score of the scale is that the higher the average score, the less familiar the learner is with the theory; the lower the average score, the more familiar the learner is with the theory; the result is shown in Figure 9.

It can be seen from Figure 9 that education majors know more about educational technology courses, and $38.20 \%$ of them know very well, while art majors do not understand this well, with $36.05 \%$ art majors. Both said that they had never heard of this course.

The status quo of learners' software skills was investigated, and the results are shown in Table 4.

It can be seen from Table 4 that the average score of learners in each software is less than 3 . The level of familiarity is also caused by the professionalism of the software itself. According to the statistical results, it can be found that there are significant differences in software skills among professional learners.

With regard to the course online learning platform, when learners encounter problems, they hope for teachers' response, with the survey results of response speed shown in Figure 10(a). Teaching requires learners to carry out independent online learning in their spare time. The survey results of how long learners think the online learning time should be after class per week are shown in Figure 10(b).

From Figure 10(a), learners expect to get more than 80\% of teachers' responses within half a day. Therefore, when developing blended teaching, tutors should ensure when learners are learning and when learners encounter problems. The teachers' reply within half a day meets the learning needs of most learners. According to Figure 10(b), the proportion of learners who study online for less than 3 hours after class is more than $80 \%$. Therefore, when designing offline learning resources, the weekly learning time should be controlled within 3 hours.

\section{Discuss}

On the starting point of learning, there are significant differences in the starting point of learners' ability level due to different majors. The learning of theoretical knowledge and software skill knowledge in educational technology courses needs to understand the degree that learners have mastered in advance. This study discusses the two aspects of learners' theory and software based on data statistics.

Because students often use different online learning resources, different ways for students to learn online learning resources are defined. Video and audio transmission is a considerable network resource. If you download resources to learn, it will take a long time and more effort. Students are more willing to participate in online learning. Therefore, from the research on the use of student resources, it can be seen that audiovisual and online courses are relatively important learning resources. If students use online learning more, it can save a lot of time. 


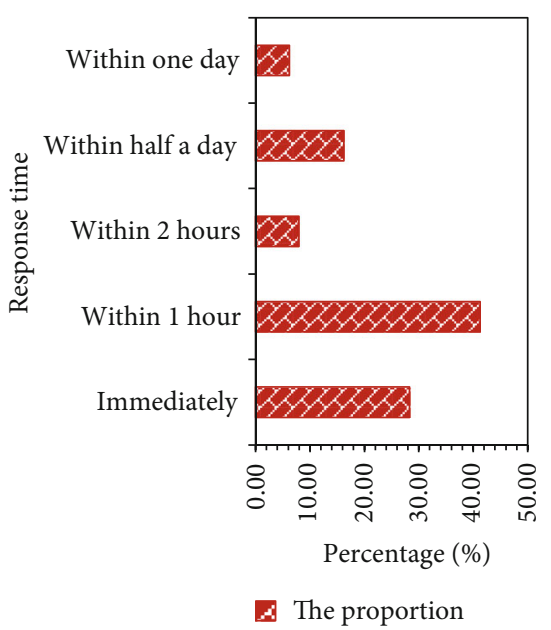

(a)

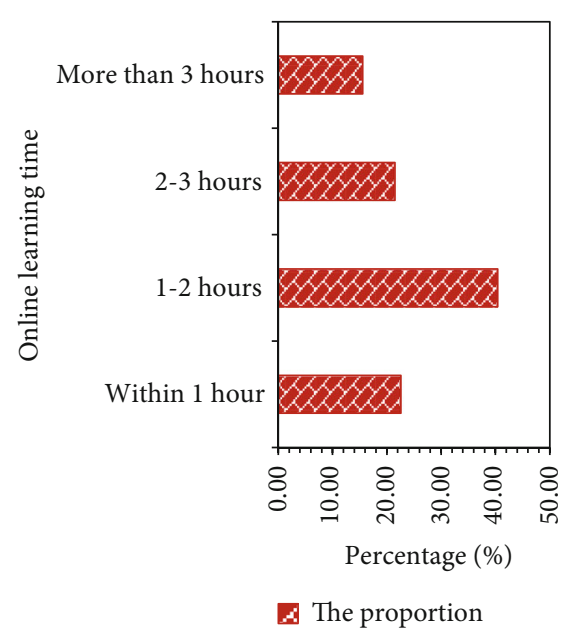

(b)

FIGURE 10: The expected response time and online learning time survey results of students.

\section{Conclusions}

The purpose of building a learning platform in the learning of educational technology courses is to help students make full use of the classroom and network to promote their more effective learning. The learning platform of educational technology courses designed in this paper not only provides a friendly platform and rich resources for learners' learning but also provides teachers with appropriate teaching modes to optimize their teaching effect. The platform realizes the complementary advantages of classroom teaching and network teaching and provides strong support for teachers and students. This platform can realize students' self-evaluation during online learning. For all, it is also easier to grasp the key and difficult points of teaching and implement individualized teaching. At the same time, it also promotes the communication between teachers and students and strengthens the interaction between teachers and students. However, when comparing and discussing with other colleges and universities, there are certain limitations and the scope of the survey is limited. At the same time, some studies may not be able to fully understand the real situation of the students, so the design research in this area needs further improvement.

\section{Data Availability}

No data were used to support this study.

\section{Conflicts of Interest}

The authors state that this article has no conflict of interest.

\section{Acknowledgments}

This work was supported by the Key research base of Humanities and Social Sciences in Sichuan colleges and Universitieskey project of Sichuan Research Center for early development and education of 0-3-year-old children "Research on the construction of diversified and integrated infant care service system" (SCLS19-01) and a doctoral innovation fund project of School of Educational Sciences of Xinjiang Normal University-Research on the development of education in Xinjiang (XJNUJKYA2015).

\section{References}

[1] A. D. Ritzhaupt, N. Valle, and M. Sommer, "Design, development, and evaluation of an online statistics course for educational technology doctoral students: a design and development case," Journal of Formative Design in Learning, vol. 4, no. 2, pp. 119-135, 2020.

[2] O. B. Olusola and B. L. Kolapo, "Pre-service teachers' perceived relevance of educational technology course, digital performance: teacher perceived of educational technology," International Journal of Technology and Educational Marketing, vol. 9, no. 1, pp. 41-54, 2019.

[3] H. Matsukawa, M. Oyama, C. Negishi, Y. Arai, C. Iwasaki, and H. Hotta, "Analysis of the free descriptions obtained through course evaluation questionnaires using topic modeling," Educational Technology Research, vol. 41, no. 1, pp. 125-137, 2019.

[4] R. S. Sletten, "Investigating flipped learning: student selfregulated learning, perceptions, and achievement in an introductory biology course," Journal of Science Education \& Technology, vol. 26, no. 3, pp. 347-358, 2017.

[5] Ü. Çakıroğlu and M. Öztürk, "Flipped classroom with problem based activities: exploring self-regulated learning in a programming language course," Educational Technology \& Society, vol. 20, no. 1, pp. 337-349, 2017.

[6] K. Huang, X. Ge, and V. Law, "Deep and surface processing of instructor's feedback in an online course," Educational Technology \& Society, vol. 20, no. 4, pp. 247-260, 2017.

[7] S. Hussain, P. K. Jamwal, M. T. Munir, and A. Zuyeva, “A quasi-qualitative analysis of flipped classroom implementation in an engineering course: from theory to practice," International Journal of Educational Technology in Higher Education, vol. 17, no. 1, pp. 1-19, 2020.

[8] L. C. Lin, I. C. Hung, and N. S. Chen, "The impact of student engagement on learning outcomes in a cyber-flipped course," 
Educational Technology Research and Development, vol. 67, no. 6, pp. 1573-1591, 2019.

[9] J. Cai, S. Zhu, Y. Tian, and H. H. Yang, "Learning from practice: improving blended learning strategies in an educational technology course," International Journal of Innovation and Learning, vol. 21, no. 4, pp. 467-480, 2017.

[10] M. F. Bayar, M. Kurt, and M. A. Haşıloğlu, "Science and technology course in educational information network a review on videos," Journal of Educational Research, vol. 6, no. 3, pp. 413420, 2018.

[11] A. Purarjomandlangrudi and D. Chen, "Exploring the influence of learners' personal traits and perceived course characteristics on online interaction and engagement," Educational Technology Research and Development, vol. 68, no. 5, pp. 2635-2657, 2020.

[12] W. Tu and M. M. Snyder, "Developing conceptual understanding in a statistics course: Merrill's first principles and real data at work," Educational Technology Research \& Development, vol. 65, no. 3, pp. 579-595, 2017.

[13] T. Rice-Bailey and K. S. Baker, "Introducing a writing coach into an MBA course: perspectives of students and coaches," Journal of Educational Technology Systems, vol. 47, no. 4, pp. 478-491, 2017.

[14] Y. C. Kuo and B. R. Belland, "An exploratory study of adult learners' perceptions of online learning: minority students in continuing education," Educational Technology Research \& Development, vol. 64, no. 4, pp. 1-20, 2016.

[15] E. Verdú, L. M. Regueras, E. Gal, J. P. de Castro, M. J. Verdú, and D. Kohen-Vacs, "Integration of an intelligent tutoring system in a course of computer network design," Educational Technology Research and Development, vol. 65, no. 3, pp. 1$25,2016$.

[16] İ. Şan and T. Aykaç, "Effect of Khan Academy-aided teaching on academic achievement in English course," Cypriot Journal of Educational Sciences, vol. 15, no. 5, pp. 1107-1116, 2020.

[17] A. E. Kan and A. Murat, "Examining the self-efficacy of teacher candidates' lifelong learning key competences and educational technology standards," Education and Information Technologies, vol. 25, no. 2, pp. 707-724, 2020.

[18] K. J. Burner, "Journaling to elicit self-regulation and academic performance in a preservice teacher technology education course," Technology, Instruction, Cognition and Learning, vol. 11, no. 2-3, pp. 219-245, 2019.

[19] L. Turpin and J. Durham, "Designing and teaching an online teacher training course: integrating critical thinking skills into the exploration of culture in an EFL setting," Journal of Educational Multimedia \& Hypermedia, vol. 26, no. 3, pp. 231-248, 2016.

[20] T. Yamamoto and T. Yabuta, "An elementary school computer programming class incorporating stepwise tasks and joint teaching with junior high school manual training course teacher," Japan Journal of Educational Technology, vol. 40, no. 3, pp. 175-185, 2016.

[21] V. Fratto, M. G. Sava, and G. J. Krivacek, "The impact of an online homework management system on student performance and course satisfaction in introductory financial accounting," International Journal of Information and Communication Technology Education, vol. 12, no. 3, pp. 76-87, 2016.
[22] Y. H. Pu, T. T. Wu, P. S. Chiu, and Y. M. Huang, "The design and implementation of authentic learning with mobile technology in vocational nursing practice course," British Journal of Educational Technology, vol. 47, no. 3, pp. 494-509, 2016.

[23] P. Stott, "The perils of a lack of student engagement: reflections of a "lonely, brave, and rather exposed" online instructor," British Journal of Educational Technology, vol. 47, no. 1, pp. 51-64, 2016.

[24] Y. Zhu, J. H. Zhang, W. Au, and G. Yates, "University students' online learning attitudes and continuous intention to undertake online courses: a self-regulated learning perspective," Educational Technology Research and Development, vol. 68, no. 3, pp. 1485-1519, 2020.

[25] I. Blau and T. Shamir-Inbal, "Writing private and shared annotations and lurking in Annoto hyper-video in academia: insights from learning analytics, content analysis, and interviews with lecturers and students," Educational Technology Research and Development, vol. 69, no. 2, pp. 763-786, 2021.

[26] Z. Lv and A. K. Singh, "Big data analysis of internet of things system," ACM Transactions on Internet Technology, vol. 21, no. 2, pp. 1-15, 2021.

[27] D. Chen, P. Wawrzynski, and Z. Lv, "Cyber security in smart cities: a review of deep learning-based applications and case studies," Sustainable Cities and Society, vol. 66, article 102655, 2020.

[28] Z. Lv, A. K. Singh, and J. Li, "Deep learning for security problems in 5G heterogeneous networks," IEEE Network, vol. 35, no. 2, pp. 67-73, 2020.

[29] Y. Li, Y. Zuo, H. Song, and Z. Lv, "Deep learning in security of Internet of things," IEEE Internet of Things Journal, 2021. 